\title{
Using the job characteristics model to compare patient care assignment methods of nurses
}

A.H. Mohamed ${ }^{1}$

$$
\text { استخدام نغوذج خسصائص العمل لمقارنة طُرُق توزيع خحمات رعاية المرضى على الممرضات }
$$

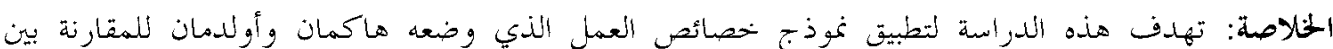

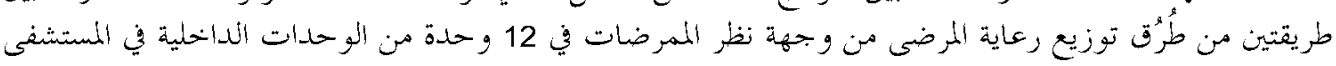

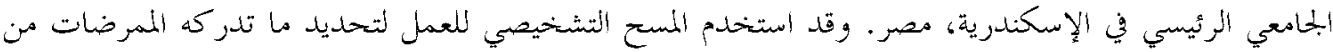

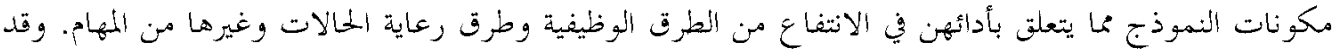

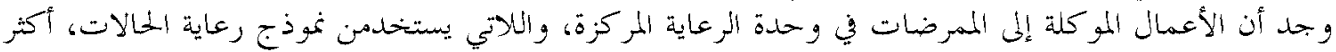

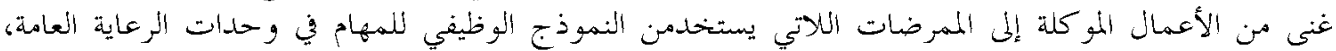

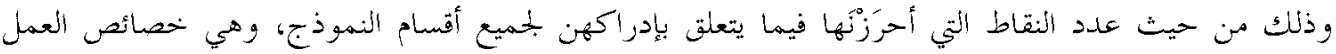

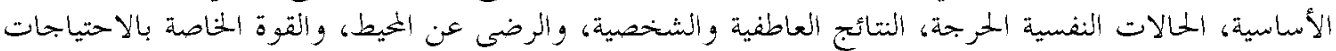
وبالنمو لندى الأفراد.

ABSTRACT The aim of this study was to use Hackman and Oldman's job characteristics model to compare 2 methods of patient care assignment as perceived by nurses in 12 inpatient units of Alexandria Main University Hospital. The job diagnostic survey was used to determine nurses' perceptions toward the components of the model in relation to their performance in utilizing the case and functional methods of patient care assignment. The jobs of intensive care unit nurses who utilized the case method were more enriched than those who utilized the functional method of assignment in the general care units, in terms of their perception scores towards all parts of the model (core job characteristics, critical psychological states, affective and personal outcomes, context satisfaction and individual growth-need strength).

\begin{abstract}
Utilisation du modèle des caractéristiques du travail pour comparer les méthodes de distribution des soins aux patients des infirmières

RESUME L'objectif de cette étude était d'utilizer le modèle des caractéristiques du travail de Hackman et Oldman pour comparer deux méthodes de distribution des soins aux patients telles qu'elles sont perçues par les infirmières dans 12 services du principal hôpital universitaire d'Alexandrie. Le job diagnostic surveya été utilisé pour déterminer les perceptions des infirmières à l'égard des éléments du modèle en rapport avec leur performance en utilisant la méthode des cas et la méthode fonctionnelle de distribution des soins aux patients. Le travail des infirmières dans les services de soins intensifs qui utilisaient la méthode des cas était plus enrichissant que celui dans les services de soins généraux utilisant la méthode fonctionnelle de distribution, d'après leurs scores de perception vis-à-vis de toutes les parties du modèle (caractéristiques principales du travail, états psychologiques critiques, résultats affectifs et personnels, satisfaction vis-à-vis du contexte et besoin d'accomplissement personnel).
\end{abstract}

${ }^{1}$ Department of Nursing Administration, Faculty of Nursing, University of Alexandria, Alexandria, Egypt. Received: 24/08/03; accepted: 03/03/04

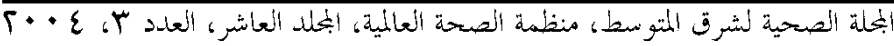




\section{Introduction}

The job characteristics model developed by Hackman and Oldham predicts what aspects of jobs reflect the level of job enrichment for employees, and how these relate to employees' individual differences and to the work outcomes required [1]. It includes 5 core job characteristics that can be applied to any job: skill variety, task identity, task significance, task autonomy and feedback (Figure 1) [1]. Skill variety is the number of different skills required in the job, while task identity means the completeness of the tasks done in the job $[1,2]$. Task significance refers to the importance of the job to the served population. Autonomy means the vertical expansion of responsibility, the amount of decision-making and independence allowed for employees. Feedback refers to the extent that the job

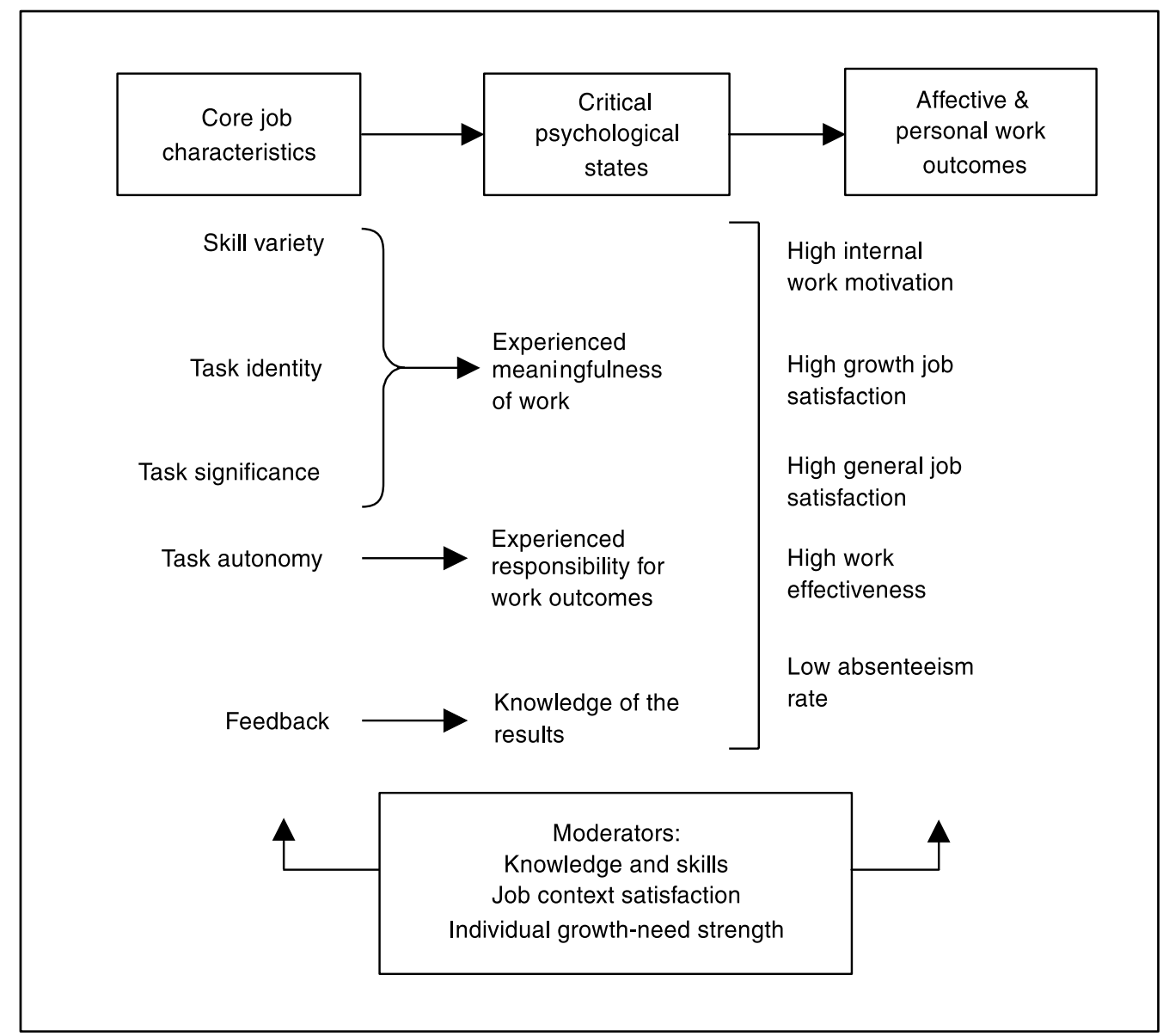

Figure 1 Job characteristics model. Source: Hackman JR and Oldham GR [1]

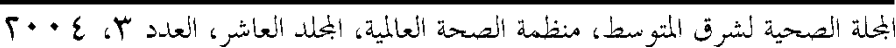


itself provides information about employees' performance [3]. These characteristics are combined into a single predictive index, called the motivating potential score [1].

The core job characteristics are in continuous interaction with the individual differences that evoke 3 critical psychological states (Figure 1) [1]. First, when the job is structured by skill variety, task identity and task significance this could lead employees to experience meaningfulness in their work. Second, is task autonomy, which leads to feelings of responsibility for the outcomes of work. Third, is feedback, which leads employees towards knowledge of the results of their work $[3,4]$.

In turn, these 3 critical psychological states lead to a set of affective and personal outcomes, namely: high internal work motivation, high growth satisfaction, high general satisfaction, high work effectiveness and a low rate of absenteeism (Figure 1) [5]. High internal work motivation refers to the degree to which the employee is willing to work and to consider the organizational objectives as a part of his/her goals. High growth job satisfaction is the achievement of the employee in overcoming challenges, succeeding and growing [6]. High general job satisfaction is the feeling derived from the overall satisfaction with the work itself. This type of satisfaction is reflected mainly in decreased rates of absenteeism among employees [6,7]. Work effectiveness captures both the quality and quantity aspects of work performance [1].

The model also depicts 3 important attributes that are identified as moderators: knowledge and skills, context job satisfaction and employee growth-need strength (Figure 1). These attributes indicate which employee will respond positively to the motivating potential score of the job and its outcomes [1]. Job-relevant knowledge and skills of employees are greatly dependent on their educational qualifications, which will reflect their perceptions toward their work outcomes [8]. Employees' perceptions of context job satisfaction include factors such as pay, supervision, co-workers and job security, and these can also affect the outcomes achieved [9]. Growth-need strength is the degree to which employees seek opportunities on the job for self-direction, learning and personal accomplishment, which in turn will determine the level of work internal motivation they perceive [10]. Such opportunities could be a set of job characteristics and attributes that the employee would like to have (pay, promotion, safety, etc.) or a combination of certain characteristics that form a specific type of job (creative, repetitive, challenging, etc.) [8].

The job characteristics model has been applied to nursing in a number of studies. According to Lang the quality of nurses' work within their job is the degree of excellence in the delivery of patient care, while the quantity indicates the number of patients assigned to nurses or the number of working hours to carry out the care needed [11]. In the United States of America, studies have focused on testing the model in terms of job enrichment, work motivation and job satisfaction in wards [12]. Another study focused on nursing jobs and satisfaction in relation to the core job characteristics [13]. These studies revealed a significant positive relationship between nurses' perceptions of the current level of job enrichment and their job satisfaction and motivation; however no empirical proof was provided to support the underlying assumption that job enrichment leads to increased work motivation and job satisfaction.

Several different methods of assigning patient care can be identified that describe

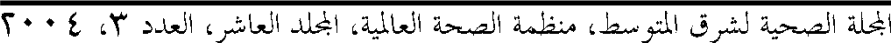


how duties and responsibilities for patient care are allocated to nurses; these include the case, functional, team, primary, modular and case management methods [1417]. In the case method, the total care of a patient is assigned to a qualified nurse for a number of patients each shift [14]. The functional method is applied by dividing patient care into tasks, such as giving baths, administering medication, taking vital signs [15]; each nurse carries out one or more of these tasks, as appropriate, according to his/her competence. The job characteristics model might be used to determine whether different methods of patient care assignment affect nurses' satisfaction and performance.

A study in Egypt, while not directly applying the model, assessed the impact of 2 different methods of nursing assignment on the quality of nursing care provided for patients in the critical care units at Qasr-elAini Hospital [18]. A highly significant difference was found in the quality of nurses' performance between the team versus the case methods of assignment. There was also a higher percentage of high quality care and average quality of care among the group of nurses using the team method as opposed to the case method. This study recommended further studies of the effect of different methods of patient care assignment on the quality of nurses' work.

The purpose of the present study was to use Hackman and Oldman's job characteristics model to compare 2 methods of patient assignment (case and functional) as perceived by nurses utilizing these methods in Alexandria Main University Hospital. It was hoped that this study could provide more knowledge about the effects of job enrichment on the work outcomes achieved though utilizing the case and functional methods of assignment and to point the way to solutions for conditions that can result in lack of motivation and job dissatisfaction for nurses.

\section{Methods}

\section{Setting and subjects}

The study was conducted in 12 inpatient hospital units of Alexandria Main University Hospital: 6 intensive care units (ICUs) that are applying the case method of patient care assignment (casualty, open heart, chest, neurosurgery, general and coronary care) and 6 general care units (GCUs) that utilize the functional method. The case and functional methods of patient care were selected since they are the ones most utilized in the ICUs and GCUs respectively at this hospital.

The subjects of this study were the 94 nurses working in the ICUs (46 professional nurses and 48 technical nurses) and the 59 technical nurses of the GCUs at the time of the study. The professional nurses were graduates of the Faculty of Nursing holding a baccalaureate degree, while the technical nurses held a diploma degree and were graduates of the secondary technical nursing school.

\section{Research tool}

The job diagnostic survey developed and validated by Hackman and Oldham [1] was used in the current study to measure all the components of the job characteristics model as applied to nursing. Respondents' perceptions are measured in 5 sections, with responses scored using 7-point rating scales (except "preferred type of job", which was scored using a 5-point scale).

1. Core job characteristics: skill variety (3 items), task identity ( 3 items), task significance (3 items), autonomy ( 3 items) and feedback (3 items). 
2. Critical psychological states: experienced meaningfulness of work (4 items), experienced responsibility of the work (6 items) and experienced knowledge of the results of the work (4 items).

3. Affective and personal outcomes: internal work motivation (6 items), growth satisfaction (4 items), general satisfaction (5 items), work quality (1 item) and work quantity $(1$ item). The work effectiveness perceived by respondents is obtained by summing the average ratings of nurses' perceptions regarding the quality and quantity of their work.

4. Satisfaction with work context: job security (2 items), pay ( 2 items), coworkers (3 items), and supervision (3 items).

5. Growth-need strength. The first subsection (6 items) determines respondents' perceptions of how much they 'would like' to have certain attributes and characteristics in their jobs. The second subsection (12 items) is used to determine respondents' perceptions toward the preferred type of job and is called 'job choice'.

The questionnaire also included information about nurses': demographic characteristics, including age, total years of experience and current unit experience.

The questionnaire was translated into Arabic and tested for content validity by 6 experts: 2 professors from the Public Health Department at the Faculty of Medicine, 2 professors from the Hospital Administration Department at the High Institute of Public Health, 1 professor from the Nursing Administration Department, and 1 professor from the Adult Nursing Department at the Faculty of Nursing, University of Alexandria.
The reliability of the questionnaire was tested using the test-retest technique. This was done by giving the questionnaire to 15 nurses in the selected settings (not included in the present study), with a time lapse of 1 month. Analysis of the data was done to estimate the test-retest correlation coefficient which was $0.52(P<0.05)$. Also, a pilot study was carried out on 15 nurses who were working in other hospital units and any necessary modifications were made based on the responses.

\section{Data collection and analysis}

Official permission for the study was obtained from the medical and nursing directors at Alexandria Main University Hospital.

Data were collected in a 6-month period from 1 January to 31 June 2000. The total number of days absent (i.e. all leave with permission such as sick, casual and annual holidays) for each nurse was calculated for the whole year from 1 January to 31 December 2000 by reviewing the absence records in the personnel department at Alexandria Main University Hospital.

Data analysis was done using Epi-Info, version 6.2 and SPSS, version 10 statistical software packages. Data were presented using descriptive statistics in the form of means, standard deviations (SD), frequencies and percentages. In addition, for each component of the research tool, a mean percentage score was computed. A score of $\geq 60 \%$ of the mean was considered high, while a score $<60 \%$ was considered low. In this way, the percentages of nurse scoring above or below average were computed. Qualitative variables were compared using chi-squared tests. Whenever the expected values in one or more of the cells in a $2 \times 2$ table was less than 5 , the Fisher exact test was used instead. Pearson correlation analysis $(r)$ was used for assessment

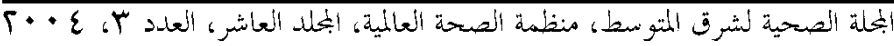


of the inter-relationships among various scores and quantitative personal characteristics. For multiple group comparisons of quantitative data, the one-way analysis of variance test (ANOVA) was used. Multiplerange Scheffe test was used to discern significant differences. For all statistical tests, significance was considered as $P<0.05$.

\section{Results}

\section{Demographic characteristics}

Table 1 demonstrates that half of the professional nurses and one-third of the tech- nical nurses working in the ICUs were in the age group 20 to $<30$ years. In contrast, the highest percentage of the technical nurses working in the GCUs $(25.4 \%)$ were in the age groups 30 to $<40$ years and 40 to $<50$ years.

Professional nurses working in the ICUs had more experience $(37.0 \%$ had between 5 to $<10$ total years of experience) compared with technical nurses in the ICUs $(37.7 \%$ with $<5$ years experience). However, technical nurses working in the GCUs had the most experience $(33.9 \%$ had between 10 to $<20$ years total experience).

Table 1 Demographic characteristics of the 3 groups of study nurses utilizing different methods of patient care assignment

\begin{tabular}{|c|c|c|c|c|c|c|}
\hline \multirow[t]{3}{*}{ Variable } & \multicolumn{4}{|c|}{ Case assignment (ICUs) } & \multirow{2}{*}{\multicolumn{2}{|c|}{$\begin{array}{c}\text { Functional assignment } \\
\text { (GCUs) } \\
\text { Technical nurses } \\
(n=59)\end{array}$}} \\
\hline & \multicolumn{2}{|c|}{$\begin{array}{l}\text { Professional nurses } \\
\qquad(n=46)\end{array}$} & \multicolumn{2}{|c|}{$\begin{array}{c}\text { Technical nurses } \\
\quad(n=48)\end{array}$} & & \\
\hline & No. & $\%$ & No. & $\%$ & No. & $\%$ \\
\hline \multicolumn{7}{|c|}{ Age (years) } \\
\hline$<20$ & 0 & 0.0 & 6 & 12.5 & 3 & 5.1 \\
\hline $20-$ & 23 & 50.0 & 16 & 33.3 & 14 & 23.7 \\
\hline $30-$ & 11 & 23.9 & 13 & 27.1 & 15 & 25.4 \\
\hline $40-$ & 10 & 21.7 & 7 & 14.6 & 15 & 25.4 \\
\hline $50-60$ & 2 & 4.4 & 6 & 12.5 & 12 & 20.3 \\
\hline \multicolumn{7}{|c|}{ Total experience (years) } \\
\hline$<5$ & 14 & 30.4 & 18 & 37.7 & 3 & 5.1 \\
\hline $5-$ & 17 & 37.0 & 11 & 22.9 & 8 & 13.6 \\
\hline $10-$ & 5 & 10.9 & 6 & 12.5 & 20 & 33.9 \\
\hline $20-$ & 3 & 6.5 & 3 & 6.3 & 9 & 15.3 \\
\hline $25-$ & 4 & 8.7 & 5 & 10.4 & 5 & 8.5 \\
\hline $30+$ & 3 & 6.5 & 5 & 10.4 & 14 & 23.7 \\
\hline \multicolumn{7}{|c|}{$\begin{array}{l}\text { Experience in current } \\
\text { unit (years) }\end{array}$} \\
\hline$<1$ & 3 & 6.5 & 6 & 12.5 & 10 & 17.0 \\
\hline $1-$ & 4 & 8.7 & 4 & 3.3 & 6 & 10.2 \\
\hline $2-$ & 10 & 21.7 & 10 & 20.8 & 17 & 28.8 \\
\hline $5-$ & 17 & 37.0 & 13 & 27.1 & 18 & 30.5 \\
\hline $5+$ & 12 & 26.1 & 15 & 31.3 & 8 & 13.6 \\
\hline
\end{tabular}

$I C U$ = intensive care unit; $G C U$ = general care unit .

$\mathrm{n}=$ total number of nurses. 
Eastern Mediterranean Health Journal, Vol. 10, No. 3, 2004

Table 2 Nurses' perceptions toward the different components of the job characteristics model according to patient care assignment method and category of nurse

\begin{tabular}{|c|c|c|c|c|}
\hline \multirow[t]{2}{*}{ Components of model } & \multicolumn{2}{|c|}{ Case assignment (ICUs) } & \multirow{2}{*}{$\begin{array}{c}\text { Functional } \\
\text { assignment } \\
\text { (GCUs) } \\
\text { Technical } \\
\text { nurses }(n=59) \\
\text { Mean score } \pm \\
\text { SD }\end{array}$} & \multirow{2}{*}{$\begin{array}{c}\text { Analysis } \\
\text { of variance } \\
\text { (F-value) }\end{array}$} \\
\hline & $\begin{array}{c}\text { Professional } \\
\text { nurses }(n=46) \\
\text { Mean score } \pm \\
\text { SD }\end{array}$ & $\begin{array}{c}\text { Technical } \\
\text { nurses }(n=48) \\
\text { Mean score } \pm \\
\text { SD }\end{array}$ & & \\
\hline \multicolumn{5}{|l|}{ Core job characteristics } \\
\hline Skill variety & $5.7 \pm 1.0^{\mathrm{bc}}$ & $5.0 \pm 1.0^{c}$ & $3.2 \pm 0.9$ & $92.93^{*}$ \\
\hline Task identity & $5.3 \pm 0.9^{b c}$ & $4.8 \pm 0.8^{c}$ & $3.3 \pm 0.9$ & $73.15^{\star}$ \\
\hline Task significance & $6.2 \pm 0.8^{c}$ & $5.8 \pm 0.8^{c}$ & $4.0 \pm 0.9$ & $111.04^{\star}$ \\
\hline Autonomy & $5.5 \pm 0.9^{\mathrm{bc}}$ & $4.8 \pm 0.9^{c}$ & $3.4 \pm 0.9$ & $74.40^{*}$ \\
\hline Feedback from job itself & $4.9 \pm 0.9^{b c}$ & $4.4 \pm 0.7^{c}$ & $3.8 \pm 0.7$ & $26.88^{*}$ \\
\hline Motivating potential score & $157.1 \pm 43.9^{b c}$ & $114.5 \pm 41.3^{c}$ & $46.7 \pm 22.3$ & $125.45^{\star}$ \\
\hline \multicolumn{5}{|l|}{$\begin{array}{l}\text { Experienced critical psychological states } \\
\text { Experienced meaningfulness of }\end{array}$} \\
\hline work & $4.0 \pm 0.4$ & $4.1 \pm 0.7$ & $4.0 \pm 0.9$ & 0.31 \\
\hline Experienced responsibility of work & $5.1 \pm 0.7^{c}$ & $4.8 \pm 0.6^{c}$ & $4.1 \pm 0.6$ & $32.36^{*}$ \\
\hline Knowledge of results & $5.0 \pm 0.7^{c}$ & $4.7 \pm 0.8$ & $4.4 \pm 0.6$ & $11.01^{*}$ \\
\hline Total & $4.6 \pm 0.4^{c}$ & $4.4 \pm 0.4^{c}$ & $4.0 \pm 0.4$ & $36.32^{*}$ \\
\hline \multicolumn{5}{|l|}{ Affective and personal outcomes } \\
\hline Growth satisfaction & $4.6 \pm 1.0^{c}$ & $4.4 \pm 0.9^{c}$ & $3.9 \pm 0.6$ & $10.28^{*}$ \\
\hline Internal work motivation & $5.1 \pm 0.6^{c}$ & $5.0 \pm 0.6^{c}$ & $4.2 \pm 0.7$ & $27.07^{\star}$ \\
\hline General satisfaction & $4.3 \pm 0.6^{\mathrm{bc}}$ & $3.9 \pm 0.7$ & $3.8 \pm 0.7$ & $10.52^{*}$ \\
\hline Absenteeism ${ }^{\mathrm{a}}$ & $31.9 \pm 20.8$ & $34.4 \pm 18.9$ & $37.0 \pm 26.5$ & 0.66 \\
\hline Quality & $5.3 \pm 0.9^{\mathrm{bc}}$ & $4.5 \pm 0.7^{c}$ & $4.0 \pm 1.0$ & $28.06^{\star}$ \\
\hline Quantity & $5.2 \pm 0.4^{\mathrm{bc}}$ & $4.4 \pm 1.1$ & $4.5 \pm 1.0$ & $8.87^{\star}$ \\
\hline Work effectiveness & $5.3 \pm 1.0^{\mathrm{bc}}$ & $4.6 \pm 0.7$ & $4.2 \pm 0.8$ & $20.33^{*}$ \\
\hline Total & $5.0 \pm 0.7^{\mathrm{bc}}$ & $4.6 \pm 0.7^{c}$ & $3.8 \pm 0.5$ & $40.26^{*}$ \\
\hline \multicolumn{5}{|l|}{ Context satisfactions } \\
\hline Satisfaction with job security & $3.4 \pm 1.2$ & $3.1 \pm 0.9$ & $3.1 \pm 0.9$ & 2.07 \\
\hline Satisfaction with pay & $5.7 \pm 0.8^{c}$ & $4.0 \pm 1.1^{c}$ & $4.0 \pm 1.1$ & $41.58^{*}$ \\
\hline Satisfaction with co-workers & $4.7 \pm 1.0^{c}$ & $4.6 \pm 0.9^{c}$ & $3.4 \pm 1.1$ & $27.85^{\star}$ \\
\hline Satisfaction with supervision & $5.0 \pm 0.9^{c}$ & $4.7 \pm 0.9$ & $4.3 \pm 0.7$ & $8.91^{*}$ \\
\hline Total & $4.7 \pm 0.7^{c}$ & $4.4 \pm 0.6^{c}$ & $3.7 \pm 0.6$ & $39.42^{*}$ \\
\hline \multicolumn{5}{|l|}{ Individual growth-need strength } \\
\hline Would like format & $6.0 \pm 0.9^{b c}$ & $5.3 \pm 0.7^{c}$ & $4.6 \pm 0.8$ & $37.04^{\star}$ \\
\hline $\begin{array}{l}\text { Job choice format } \\
\text { Combined growth-need strength }\end{array}$ & $3.3 \pm 0.6$ & $3.4 \pm 0.5$ & $3.2 \pm 0.4$ & 1.91 \\
\hline score & $5.3 \pm 0.8^{\mathrm{bc}}$ & $4.5 \pm 0.7^{c}$ & $4.5 \pm 0.5$ & $22.82^{*}$ \\
\hline
\end{tabular}

a Absenteeism is mean $\pm S D$ number of days absence in the year.

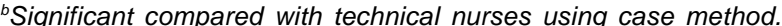

'Significant compared with technical nurses using functional method.

*P $<0.05$.

$I C U=$ intensive care unit; $G C U=$ general care unit.

$\mathrm{n}=$ total number of nurses.

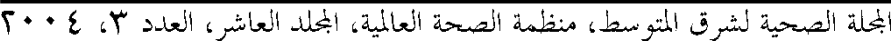


Conversely, length of experience in the current units showed a similar profile across the 3 groups; $37.0 \%$ of the professional nurses in the ICUs compared whith $30.5 \%$ of the technical nurses in the GCUs had 5 years of experience in the current unit, while $31.3 \%$ of the technical nurses in the ICUs had more than 5 years.

\section{Perception scores for different components of the model}

Table 2 shows the mean \pm SD scores in nurses' perceptions towards the different components of the job characteristics model, comparing the professional and technical nurses who utilized the case method of assignment in ICUs and the technical nurses who utilized the functional method of assignment in the GCUs. There were statistically significantly differences in perception scores between the 3 groups of nurses for all components of the model, except for experienced meaningfulness of work, absenteeism, satisfaction with job security and job choice.

Table 2 also shows that, compared with technical (ICU) and functional (GCU) nurses, the professional nurses working in the ICUs had the highest mean perception scores, except for experienced meaningfulness of work and job choice (technical nurses in the ICUs had higher mean scores for these 2 components).

The technical nurses working in the GCUs had the highest rates of absenteeism (mean $37.0 \pm 26.5$ days absence in the year) $(F=0.66)$. No statistical significant difference could be detected between the mean perception scores of the technical nurses using the case method and those using the functional method of assignment in relation to knowledge of results, general satisfaction, quantity, work effectiveness and satisfaction with supervision.

\section{Above and below average perception scores}

Table 3 shows the percentage of nurses scoring higher than average ( $\geq 60 \%$ of the mean perception score) and lower than average $(<60 \%$ of the mean score $)$ on each component of the job characteristics model. There were significant differences between the 3 groups of nurses in the percentages scoring higher/lower on perceptions for all the different components of the model (chi-squared test), except experienced meaningfulness of work, satisfaction with job security and satisfaction with supervision.

In the core job characteristics section of the model, the percentage of professional nurses utilizing the case method who scored above average ranged from $93.5 \%$ for feedback from the job to $73.9 \%$ for task identity and autonomy. For technical nurses utilizing the case method the range was from $87.5 \%$ for feedback to $50.0 \%$ for skill variety. For the technical nurses utilizing the functional method the range was from $50.8 \%$ for task significance to $27.1 \%$ for motivating potential score.

In the section on critical psychological states, the highest percentage of professional nurses using the case method of assignment scored above-average for experienced responsibility of work $(89.1 \%)$, similar to the technical nurses utilizing the same method (81.3\%). Significantly more nurses utilizing the functional method of assignment $(76.3 \%)$ gave a lower than average score in this section compared with nurses using the case assignment method (19.6\% of professional nurses and $33.3 \%$ of technical nurses scoring lower than average).

In the section on affective and personal outcomes, $93.5 \%$ of the professional nurses, and $85.4 \%$ of the technical nurses utiliz-

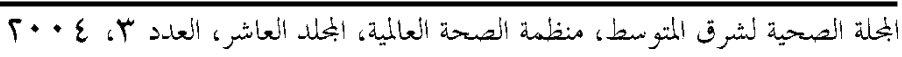


\begin{tabular}{lc}
\hline Eastern Mediterranean Health Journal, Vol. 10, No. 3, 2004 & 397
\end{tabular}

Table 3 Percentage of nurses scoring higher $(\geq 60 \%)$ or lower $(<60 \%)$ than the mean score for each component of the job characteristics model according to patient care assignment method and category of nurse

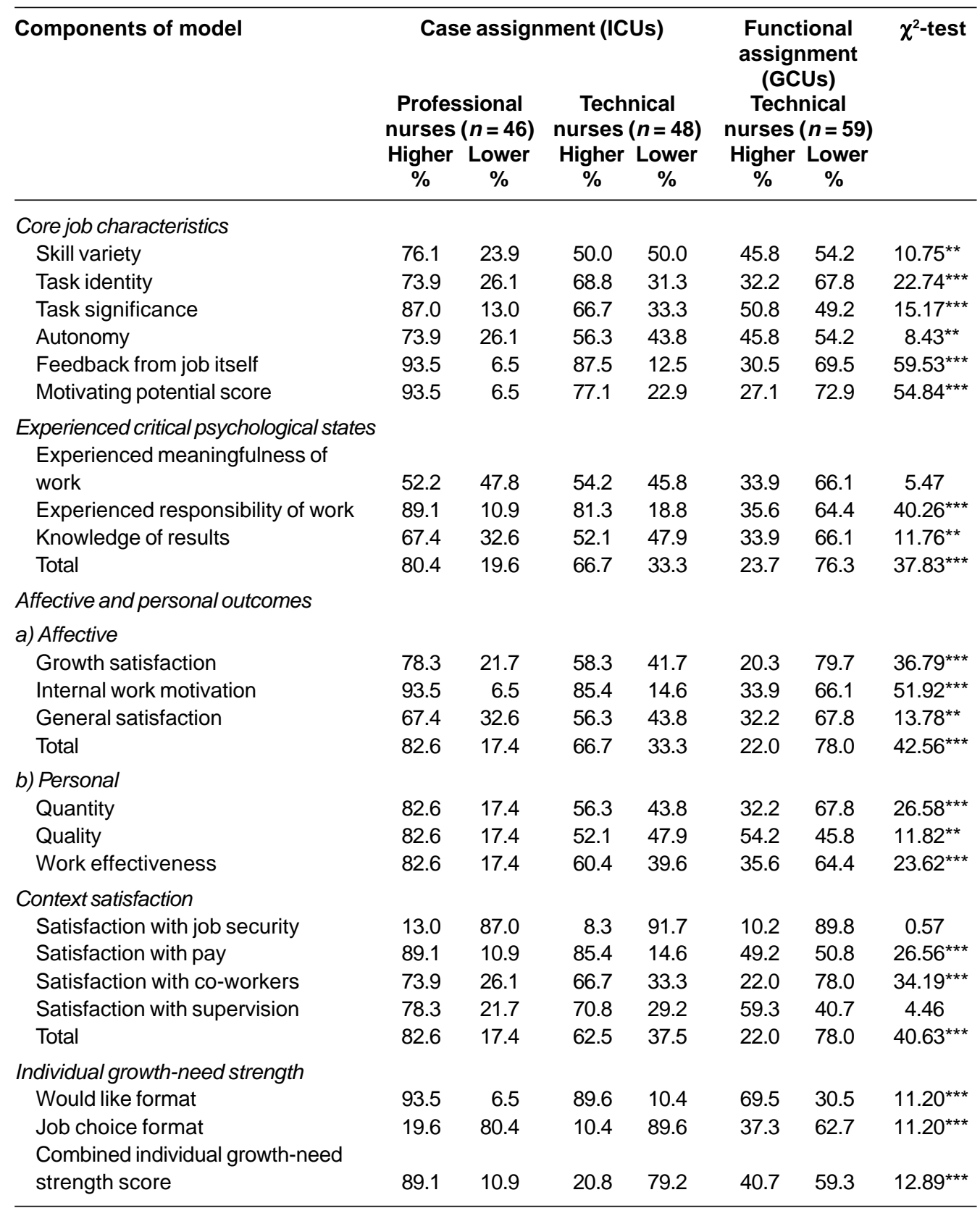

${ }^{* *} \mathrm{P}<0.01 ;{ }^{* * *} \mathrm{P}<0.001$

$I C U=$ intensive care unit; $G C U=$ general care unit.

$\mathrm{n}=$ total number of nurses.

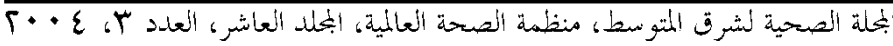


ing the case method, scored above average for internal work motivation, whereas those utilizing the functional method perceived work quality as the highest component in this section $(54.2 \%$ scoring above average).

In the context satisfaction section of the model, $89.1 \%$ and $85.4 \%$ of professional and technical nurses respectively utilizing the case method scored above average for satisfaction with pay compared with only $49.2 \%$ of technical nurses utilizing the functional method. For technical nurses using functional assignment, the highest percentage scoring above average (59.3\%) was for satisfaction with supervision

In the section on individual growthneed strength, $93.5 \%$ of the professional nurses and $89.6 \%$ of the technical nurses utilizing the case method of assignment compared with $69.5 \%$ of those utilizing the functional method of assignment scored higher than average for the availability of different characteristics and attributes that they 'would like' in their work.

\section{Correlations between scores for core job characteristics and other components of the model}

Table 4 presents the correlations between the nurses' overall perception scores for core job characteristics and other components of the model. For professional nurses utilizing the case method, there were significant positive correlations for experienced critical psychological states $(r=0.53)$, affective and personal outcomes $(r=0.63)$, and job context satisfaction $(r=0.50)$. For technical nurses utilizing the case method, the same factors showed significant positive correlations, and also for individual growth-need strength score $(r=0.58)$. On

\begin{tabular}{|c|c|c|c|}
\hline \multirow[t]{2}{*}{ Components of model } & \multicolumn{2}{|c|}{ Case assignment (ICUs) } & \multirow{2}{*}{$\begin{array}{c}\text { Functional } \\
\text { assignment (GCUs) } \\
\text { Technical nurses } \\
(n=59) \\
r\end{array}$} \\
\hline & $\begin{array}{c}\text { Professional nurses } \\
(n=46) \\
r\end{array}$ & $\begin{array}{c}\text { Technical nurses } \\
(n=48) \\
r\end{array}$ & \\
\hline $\begin{array}{l}\text { Experienced critical psychological } \\
\text { states }\end{array}$ & $0.53^{*}$ & $0.55^{\star}$ & 0.08 \\
\hline $\begin{array}{l}\text { Affective and personal outcomes } \\
\text { Absenteeism } \\
\text { Quality } \\
\text { Quantity }\end{array}$ & $\begin{array}{l}0.63^{*} \\
0.07 \\
0.25 \\
0.06\end{array}$ & $\begin{array}{l}0.58^{*} \\
0.05 \\
0.21 \\
0.14\end{array}$ & $\begin{array}{l}0.41^{*} \\
-0.09 \\
-0.001 \\
-0.21\end{array}$ \\
\hline Work effectiveness & 0.17 & 0.28 & -0.10 \\
\hline Context satisfaction & $0.50^{\star}$ & $0.55^{\star}$ & 0.55 \\
\hline $\begin{array}{l}\text { Combined individual growth-need } \\
\text { strength }\end{array}$ & 0.06 & $0.58^{\star}$ & 0.12 \\
\hline
\end{tabular}

$\mathrm{r}=$ correlation coefficient; ${ }^{\mathrm{A}} \mathrm{P}<0.05$.

$I C U=$ intensive care unit; $G C U=$ general care unit

$\mathrm{n}=$ total number of nurses. 
the other hand, for the technical nurses utilizing the functional method, a positive correlation was founded between the overall perception scores for core job characteristics and their affective and personal outcomes score $(r=0.41)$.

\section{Correlations between overall perception scores and experience}

Table 5 presents the correlations between nurses' overall perception scores on different components of the model and their age, total years of experience and years of experience working in the current unit.

For professional and technical nurses utilizing the case method of assignment, the correlations were statistically significant between each of total years of experience and years of experience working in the current unit and total score on the core job characteristics section of the model $(r=$ 0.31 and $r=0.32$ respectively).

Similarly, for the professional nurses utilizing the case method of assignment, there were statistically significant correlations between their scores towards experienced critical psychological states and their total years of experience and years of experience in the current unit ( $r=0.32$ and $r=$ 0.39 respectively). For affective and personal outcomes, a similar correlation was revealed between the score for quality of work and their years of experience in the current unit $(r=0.31)$.

Alternatively, for the technical nurses utilizing the case method, significant negative correlations were found between each of age and total years of experience and overall scores of perceptions towards core job characteristics ( $r=-0.39$ and $r=-0.35$ respectively) and experienced critical psychological states $(r=-0.40$ and $r=-0.30)$. Similar negative correlations were seen between the total years of experience and their scores for perceptions about the qual- ity and quantity of their performance ( $r=-$ 0.30 and $r=-0.29$ respectively) and combined individual growth-need strength ( $r=$ -0.42 ).

For the technical nurses utilizing the functional method, statistically significant positive correlations were found between each of their age, total years of experience and current unit experience and overall perception scores in relation to affective and personal outcomes ( $r=0.38, r=0.43, r=$ $0.32)$, absenteeism $(r=0.47, r=0.43, r=$ $0.42)$, work effectiveness $(r=0.38, r=$ $0.43, r=0.32)$ and context satisfaction $(r=$ $0.26, r=0.43, r=0.30$ ). Furthermore, significant correlations were shown between the overall score of their perceptions regarding core job characteristics and their length of experience in the current unit $(r=$ 0.32 ), and between the overall score of their perceptions about the quality of work and their total years of experience $(r=$ $0.39)$.

\section{Discussion}

Studying which characteristics of jobs make work more interesting and meaningful to employees has received much attention by organizational researchers in recent years $[19,20]$. This could be a result of the importance of understanding and predicting such outcomes as internal work motivation and job satisfaction, and the mediating effects of knowledge and skills, context satisfaction and individual growthneed strength $[21,22]$.

The present study showed that the professional and technical nurses who were working in the ICUs and utilizing the case method of assignment scored significantly higher on their perceptions of experienced responsibility of work outcomes than nurses who were utilizing the functional method

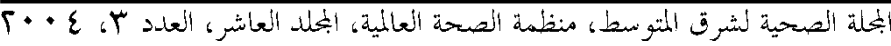




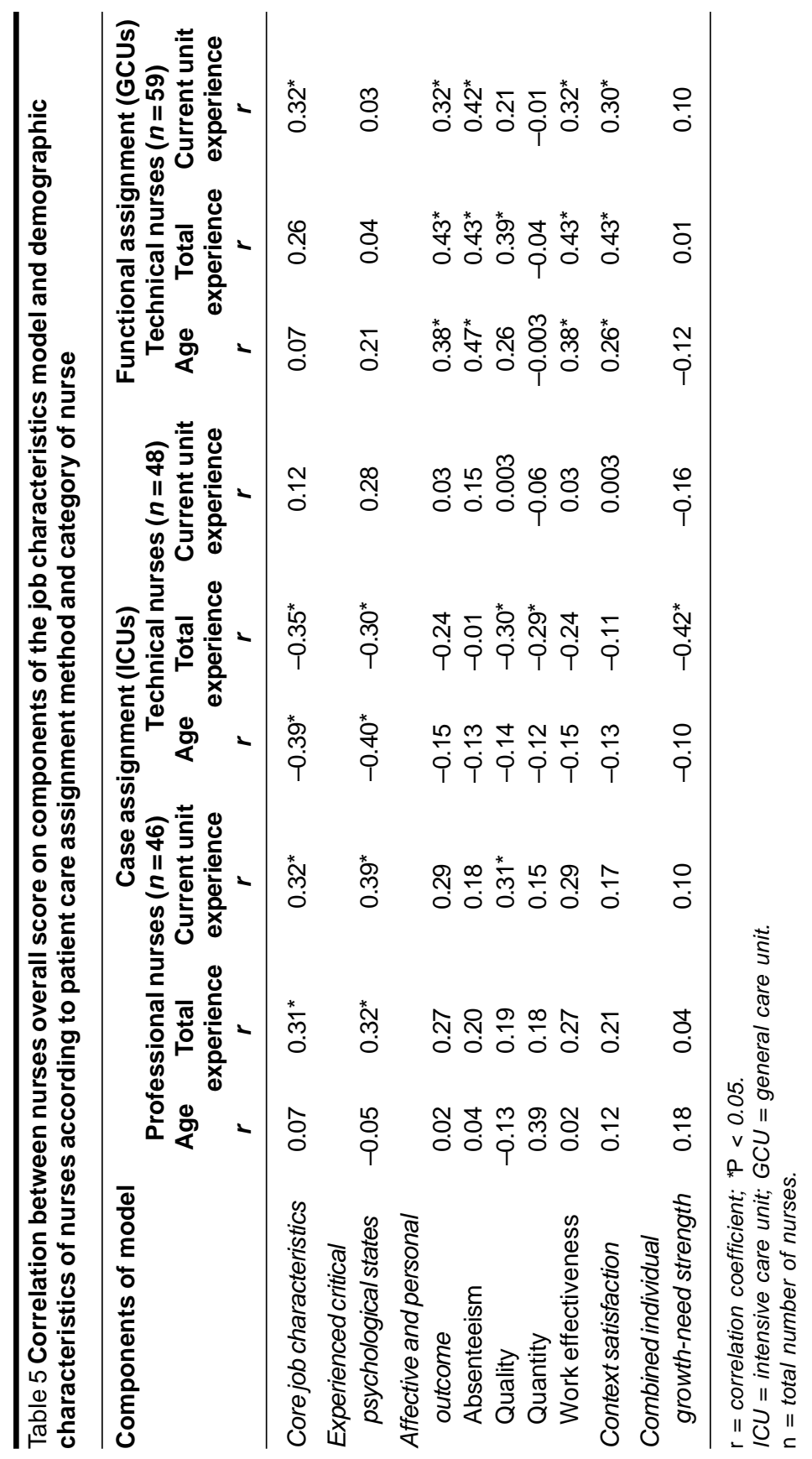

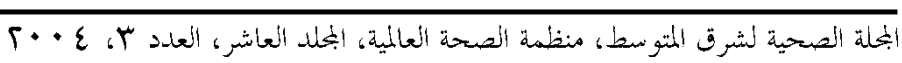


of assignment. In addition, the professional nurses who were utilizing the case method of assignment scored significantly higher for the experienced knowledge of result of their work; however, no significant difference was detected in relation to experienced meaningfulness of work among the different categories of nurses. These findings could be attributed to the characteristics of the case method of assignment that is used in ICUs which enrich the work through combining tasks, forming work units, establishing client relationships, vertically loading the job and opening up feedback channels [23-25]. ICU nurses who were utilizing the case method scored significantly higher on perceptions of the core job characteristics than other nurses.

First-line nurse managers are responsible for managing each inpatient care unit, including assignment of duties, supervising and evaluating the performance of the junior nurses. Re-assigning most of these duties to the more experienced and qualified professional nurses could enhance the degree to which professional nurses experience responsibility and knowledge of the results of their work. However, the dominant role of the medical staff over the nurses, when there are no clear policies and responsibilities for each group, could lead to feelings of meaningless of the whole work for the nurses. These findings are also supported by the positive correlations between the overall scores of the core job characteristics and the experienced critical psychological states, as well as the relationship between these 2 components and nurses' experience, both total and in the current unit. In this respect, Vestal [16] stated that attitudes and behaviour are reinforced by physicians as well as hospital administrators who believe that nurses should follow doctors' orders and hospital rules unquestioningly.
The present study indicates that the professional and technical nurses utilizing the case method of assignment scored significantly higher than those utilizing the functional method of assignment on perceptions of internal work motivation, growth satisfaction and quality of their performance as outcomes of their job. These findings could be explained by the high perception scores for core job characteristics and satisfaction with pay and co-workers for ICU nurses, which are considered as moderators between these characteristics and their affective and personal outcomes. The payment system in the ICUs in the present study may provide more incentives for the ICU nurses who are utilizing the case method of assignment than the others due to their excessive workload; however, there are no marked differences in the financial rewards between the professional and technical nurses of the ICUs based on their educational level and years of experience. In addition, the case method of assignment allocates responsibilities clearly, which in turn decreases the friction between nurses and enhances their perceptions of satisfaction with co-workers. These findings are consistent with Rodel, who explained that individuals who are relatively satisfied with pay, co-workers and supervision will respond more positively to an enriched job [13]. Furthermore, whenever individuals are satisfied with the work context, and have attained relatively high growth-need strength, which is consistent with the results of the present study, then a very high level of internal work motivation would be expected [26,27]. Leonard et al. [28] and Ingram [29] have explained that it is the quality and not the quantity of nursing care that reflects differences in the core characteristics and effectiveness level of nursing jobs. However, they have claimed that it is unwise to generalize this to differ-

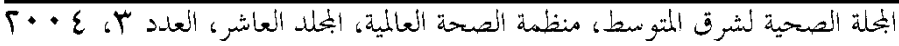


ent professional settings. Contrary to popular nursing belief, the method used to organize the delivery of care may have only a relatively small influence on a particular nurse's assessment of her/his job quantity and quality.

It is obvious that a disparity exists between the expectations of the different categories of nurses, based on the skills and challenges inherent in the work they perform. This could explain the high scores of the professional nurses using case assignment on the critical analysis of the job attributes they 'would like'. These findings are supported by Rodel's explanation that jobs with high motivating potential create opportunities for considerable self-direction, learning and personal accomplishment at work [13]. Nonetheless, not all individuals appreciate such opportunities, even among nurses who are capable of performing very competently. In contrast, a positive correlation was found between the overall score of the perceptions about the core job characteristics and the individual growth-need strength of the technical nurses only who were utilizing the case method of assignment.

The present study also reflects the significant positive relationship between the overall perceptions of professional nurses about the core job characteristics and their age and years of experience. In contrast, these relationships were negative for the technical nurses who were working in the ICUs. These findings could be explained in the light of increasing responsibilities, due to age and advanced educational level, of professional nurses for management of the whole inpatient unit, especially in the absence of the head nurse. Conversely, the more experienced technical nurses are assigned to carry out the paramedical and indirect patient care, such as checking medication storage and writing requisi- tions, while the newly appointed nurses carry out an active and direct role in patient care. Nonetheless, it has been suggested by Reed [29] that education and experience in general develop the skills of the nurse towards being more productive and are associated with nurses' positive attitudes towards their job.

The study also indicated positive correlations between age, total and current unit experience and some components of the job characteristics model as perceived by nurses utilizing the functional method of assignment in the GCUs. These findings may suggest that the functional method of assignment is suitable in terms of the type and amount of care provided, equipment and supplies and that these match to a great extent the qualifications of nurses in these units especially their increased age and experience. These findings are supported by the positive correlation between their overall score on core job characteristics and on affective and personal outcomes. In this respect, Kivimaki [12] noted that the functional method provides more flexibility in distributing separate tasks based on the needs of patients, workload and the nurses present in term of their personal characteristics such as their age and experience. This method could match with the nature of lower workload in the GCUs than in ICUs which lead nurses to experience some achievements in their affective and personal outcomes and context satisfaction corresponding to their core job characteristics.

A significant positive correlation was revealed in the present study between the rate of absenteeism and the age and years of experience of nurses utilizing the functional method of assignment. This result could be explained in the light of increased age and years of experience of this group of nurses who are allotted more days of

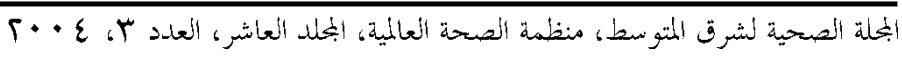


absence and it could also be related to low scores of job satisfaction derived from less job enrichment experienced among nurses utilizing the functional method of assignment. According to Hackman and Oldham [1], changes in jobs that increase internal motivation might subsequently lead to decreased absenteeism for more competent employees and increased absenteeism for their less competent co-workers. Any overall indicator of absenteeism for the work group as a whole would be misleading because of the different effects of the change on the absence rate of the two subgroups.

\section{Conclusions}

The present study revealed interesting data that provides partial support for a construct correlation among the components of the job characteristics model as applied to nurses utilizing different methods of patient assignment. It is of interest to find that the jobs of ICUs nurses who utilized the case method of assignment were more enriched than those who utilized the functional method of assignment in the GCUs, as reflected in their perceptions of all sections of the model.

Further research is needed into (1) the motivational effects of job enrichment by employing case method interventions at the GCUs where the functional method of assignment is utilized; and (2) the effect of changes in the core job characteristics of nurses on the quality of patient care provided.

\section{Recommendations}

Based on the findings of this study, the following recommendations are suggested:

- Standard organization screening procedures should be established to match the skills, abilities and the growth-need strength of nurses with the requirements of the job.

- Nurse managers should enrich the job of nurses who are utilizing the functional method of assignment by rotating them periodically between ICUs and the general care units.

- Nurses who are utilizing the case method of assignment could be given more responsibility and control over their performance and the ability to take decisions and to use other methods of patient care assignment (such as the team and primary care methods).

- Nurse managers should develop and maintain measurable criteria to assess the quality and quantity of nurses' performance.

- Periodical counselling between nurse managers and nurses should be conducted to discuss their feelings, interests and views in relation to their job, and to deal with dissatisfactions, as a part of the manager's supervisory role.

\section{References}

1. Hackman JR, Oldham GR. Work design. Reading, Massachusetts, AddisonWesley, 1980:114-21.

2. Pilon BA. Outcomes and surprises of work redesigning: how other leaders are coping with changes. Nursing management, 1998, 29(8):44-5.

3. Huber D. Leadership and nursing care management. Philadelphia, WB Saunders, 2000:151-2.

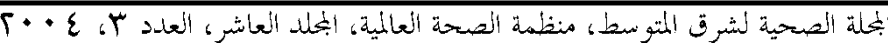


4. Douthit MW. Job satisfaction returns to human and social capital. Journal of behavioral and applied management, 2000, 1(1):67.

5. Donovan JJ, Radosevich DJ. The moderating role of goal commitment on the goal difficulty-performance relationship: a meta-analytic review and critical reanalysis. Journal of applied psychology, 1998, 83:308-15.

6. Steers RM, Black JC. Organizational behavior, 5th ed. New York, Harper Collins, 1994:95-101.

7. Omachonu VK, Swift JA, Ross JE, eds. Principles of total quality, 3rd ed. Florida, St. Lucie Press, 1999:335.

8. Sabiston JA, Laschinger HK. Staff nurse work empowerment and perceived autonomy. Journal of nursing administration, 1995, 25(9):42-50.

9. Mondy RW, Premeaux SR. Management: concepts, practices, and skills, 6th ed. Boston, Allyn and Bacon, 1993:317-20.

10. Bogin E. From staff to dream team. Financial executive, 1995, January/February: 54-6.

11. Lang NM. Issues in quality assurance in nursing. In: Issues in evaluation research, ANA Publications No. G-124, 1976:45-56.

12. Kivimaki $M$, Voutilainen $P$, Koskinen $P$. Job enrichment, work motivation, and job satisfaction in hospital wards: testing the job characteristics model. Journal of nursing management, 1995(3):87-91.

13. Rodel RR, Nystram PC. Nursing jobs and satisfaction in relation the core job characteristics. Nursing management, 1988, 19(2):34-8.

14. Lawler E. High involvement management. Personnel management, 1994, 26 (8):53.
15 Gillies DA. Nursing management: a system approach, 3rd ed. Philadelphia, WB Saunders, 1994:215-9.

16 Vestal KW. Nursing management: concepts and issues, 2nd ed. Philadelphia, JB Lippincott, 1995:40-2.

17. Marquis BL, Huston CJ. Leadership roles and management functions in nursing: theory and application, 2nd ed. Philadelphia, JB Lippincott, 1996:18796.

18. Fekry NE, Al-Badry M. The impact of two different methods of nursing assignment on the quality of care provided for patients in critical care units at Kasr Al-Eini Hospital. New Egyptian journal of medicine, 1994, 10(10):441-6.

19. Wise Y. Leading and managing in nursing. St Louis, Mosby, 1995:412-22.

20. Tappen R. Nursing leadership and management: concept and practice, 3rd ed. Philadelphia, FA Davis, 1995:445-3.

21. Behson SJ, Eddy ER, Lorenzet SJ. The importance of the critical psychological states in the job characteristics model: a meta-analytic and structured equations modeling examination. Current research in social psychology, 2000, 5:1-14.

22. Kelly K. Managing nursing care: promise and pitfalls. Series on nursing administration. St Louis, Mosby, 1993:15-8.

23. Morrison M. Professional skills for leadership: foundation of a successful career. St Louis, Mosby, 1993:416-22.

24. Dawood NI. Predicators for nurses' turnover in private and governmental hospitals [MSc Thesis]. University of Alexandria, Egypt, 2001:12-25.

25. Csikszentmihalyi A. Flow: the psychology of optimal experience. New York, Harper and Row, 1990:235-9. 
26. Hersey $\mathrm{P}$, Blanchard $\mathrm{KH}$, Johnson DE. Management of organizational behavior: leading human resources, 8th ed. New Jersey, Prentice Hall, 2002:72-9.

27. Renn RW, Vandenberg RJ. The critical psychological states: an underrepresented component in job characteristics model research. Journal of management, 1995, 21:279-303.

28. Leonard NH, Scholl RW, Beauvais LL. Organizational member self concept in the organizational adaptation and change process. Annual Meeting of the Academy of Management, 1997, 8:5-17 (http://www.cba.uri.edu/Scholl/Papers/ SC Change.html, accessed 15 December 2004).

29. Ingram H. Teamwork: a force for organizational improvement. Management literature in review, 1999, 1:1-3.

\section{Mursing and midwifery services: strategic directions 2002-2008}

The Strategic directions for strengthening nursing and midwifery services provide an evidence-based framework for action that will be undertaken by the World Health Organization and its partners to support countries dedicated to improving the quality of nursing and midwifery services. There are five key areas requiring intervention: Human resources planning, Management of personnel, Evidencebased practice, Education and Stewardship. This document can be used as a guide for action at the national level and to provide the basis for future policy dialogue at subnational levels. It consists of two sections. Part I introduces the strategic directions, key result areas and objectives with the expected results to achieve them. Part II discusses how nursing and midwifery services form an integral part of health services. Further information about nursing and midwifery services at the World Health Organization can be obtained at: http://www.who.int/health-services-delivery/nursing/index.htm

البحلة الصحية لشرق المتو مط، منظمة الصحة العالمية، البحلد المعاشر، العلدد ب، ع +. 